\title{
1. Introduction: global mangrove loss and economic development
}

\author{
Edward B. Barbier and Mark Cox
}

\section{INTRODUCTION}

Mangrove, or 'mangal', systems are the sub-tropical and tropical equivalents of the temperate coastal and estuarine salt marsh system. They are essentially forest-based systems that tolerate salt and occupy the intertidal zone between land and sea. Although mangroves are generally found within $25^{\circ}$ North and South of the Equator, they can be found in some northern latitudes as high as $32^{\circ}$ (Maltby 1986).

Mangroves line one-quarter of the world's tropical and sub-tropical coastlines, covering an area of between 190000 and 240000 square kilometers $\left(\mathrm{km}^{2}\right)$ globally (Kelleher et al. 1995). Approximately 117 countries and territories have mangrove resources within their borders (WCMC 1994). Indonesia has the largest area of mangrove forest estimated at 4.5 million hectares (ha). Nigeria, Australia, Mexico and Malaysia have the next largest areas of mangrove forest, estimated at around 1 to 2 million ha (WRI 1996). Mangroves are very important to many tropical and sub-tropical countries, as they serve to protect coastlines from tidal waves, sea erosion and hurricanes. Furthermore, they are highly productive natural ecosystems, and provide nutrients and shelter for many commercially important aquatic organisms (Deegan et al. 1988; Mitsch and Gosselink 1993; Mooney et al. 1995; WCMC 1994; WRI 1996).

Today, mangroves are one of the world's most threatened ecosystems, and are rapidly disappearing in many tropical countries where they were once abundant. For example, Malaysia may have lost 17 per cent of its mangrove area between 1965 and 1985, India as much as 50 per cent between 1963 and 1977, and the Philippines as much as 70 per cent between 1920 and 1990 (WRI 1996). Many of the other countries in Asia, Latin America and Africa have lost between 30 and 70 per cent of their mangrove area in the last 30 to 40 years (Spalding et al. 1997; WRI 1996). In some countries, such as Thailand, the rate of mangrove loss has been more recent yet extremely rapid. Over 1975-93 the area of mangroves in Thailand has virtually halved, from 312700 ha to 168683 ha (Sathirathai 1998). 
While there are many reasons for the destruction of mangrove forests, including increasing population pressure and coastal development, the demand for land by key primary sector economic development activities, such as mining, conversion to salt ponds, agricultural and aquacultural expansion, and over-harvesting of the forests, has been the largest factor in recent years. By far the most important of these activities has been the expansion of aquaculture ponds, especially for shrimp production, into mangrove forests (Aksornkoae et al. 1986; Spalding et al. 1997; WRI 1996). Shrimp aquaculture has been responsible for mangrove deforestation in many countries, but is especially evident in South East and South Asia (Kongkeo 1997). ${ }^{1}$ The problem of mangrove conversion has been exacerbated over the past two decades, given the growing importance of shrimp farming to the export earnings of tropical countries. For example, in Bangladesh shrimp farming contributes 8 per cent to total export earnings (Raha and Alam 1997). In Thailand, the total value of export earnings for shrimp in the late 1990s was around US\$1-2 billion annually (Jitsanguan et al. 1999; Tokrisna 1998).

This recent trend of converting mangroves for commercially profitable land uses and development has led to massive mangrove loss worldwide. The result has been severe disruption to the important ecological and economic functions normally performed by undisturbed mangrove systems. In many countries and regions, mangrove deforestation is contributing to fisheries decline, degradation of clean water supplies, salinization of coastal soils, erosion and land subsidence, as well as release of carbon dioxide into the atmosphere (Barbier and Strand 1998; Ruitenbeek 1994; Sathirathai 1998; Spalding et al. 1997; WRI 1996). In Thailand, the welfare losses associated with the impacts of mangrove deforestation on coastal fisheries in Surat Thani Province were estimated to be around US\$21 to 52 per ha (Sathirathai and Barbier 2001).

Although the loss of mangroves and the resulting environmental effects are well publicized, there have been few studies of the economic causes of mangrove deforestation. In the following section, we develop a basic model of economic activity and mangrove conversion, in which the demand for land by converting activities leads to mangrove loss. From this model, a relationship is established between remaining mangrove area, the level of economic activity and other important causative factors. Mangrove area is expected to be a decreasing function of aggregate economic activities, such as aquaculture and agricultural expansion, that depend on the conversion or depletion of mangroves, and to be increasing with the amount of environmental protection. Ecological and coastal conditions, the accessibility of mangrove areas and institutional factors such as political stability should also have an influence. Although we would ideally like to conduct a pooled cross-sectional and time series analysis of mangrove deforestation across all countries, to date the best available data source on mangrove areas worldwide contains only a single-year 
estimate of mangrove area by country (Spalding et al. 1997). We therefore estimate our mangrove area relationship empirically through a cross-sectional analysis of 89 countries. We also analyze two important sub-samples, middle and low-income economies and countries with mangrove areas greater than 25 $\mathrm{km}^{2}$.

\section{A MODEL OF ECONOMIC ACTIVITY AND MANGROVE CONVERSION}

Suppose that there are $J$ different sectors, or activities, in the coastal area of an economy that depend in some way on the conversion or depletion of mangroves. For example, agriculture, aquaculture, salt production and residential or industrial construction would involve conversion of mangrove lands. Logging, charcoal making, tannin production and other activities that depend on depleting mangrove forest resources could also lead to a loss of mangrove areas. Although these activities may be highly diverse, their production relationships could be represented in a similar way, namely as a function of converted mangrove area and other inputs.

Thus assume that the aggregate production of all $J$ economic sectors that lead to mangrove loss can be represented by a single production relationship and total output, $y$. At any time $t$, the total stock of $1, \ldots, K$ inputs (for example, labor and capital) available for producing this output can be represented by the vector, $\boldsymbol{x}$. However, only $\boldsymbol{x}_{1}$ of these inputs are used directly in the production of $y$. The remaining $x_{2}$ units are used to convert mangrove area, $A$, which of course are also an input for producing $y$. Thus the basic cost-minimizing level of production for $y$ can be defined as:

$$
C(w, y)=\min _{x} w x
$$

Subject to:

$$
\begin{gathered}
y=F\left(x_{1}, A\right) \\
A=A\left(\mathrm{x}_{2}, \alpha\right) \\
x=x_{1}+x_{2}
\end{gathered}
$$

Equation (1.2) is the aggregate production function for $y$, which is assumed to exhibit the standard properties with respect to its arguments, $x_{1}$ and $A$. Equation (1.3) is the relationship for the level of mangrove conversion, $A$, which is an increasing function of the amount of inputs allocated to conversion, $x_{2}$, 
and a range of exogenous factors, $\alpha$, that may influence the 'accessibility' of mangrove areas available for conversion, including roads, coastal infrastructure and concentration of populations in coastal areas. Equation (1.4) indicates that all inputs, $\boldsymbol{x}$, can be used either directly in production of $y$ or for mangrove conversion, with $\boldsymbol{w}$ being the corresponding vector of input prices.

It follows from the above relationships that the conditional factor demand for any input, $x_{i k}$, can be defined as:

$$
x_{i k}=x_{i k}(w, y, a), \frac{\partial x_{i k}}{\partial w_{i k}}<0, \frac{\partial x_{i k}}{\partial w_{1}}>0, \frac{\partial x_{i k}}{\partial y}>0, i=1,2 k=1, \ldots, K k \neq 1 .
$$

That is, each $k^{\text {th }}$ input used either directly for production, $x_{1 k}$ or for mangrove conversion $x_{2 k}$, is decreasing in its own price, $w_{k}$, but increasing with respect to other input prices, $w_{l}$ and output, $y$. The corresponding cost-minimizing vector of inputs that is used for mangrove conversion is defined as $x_{2}=x_{2}(w$, $y, \alpha$ ), and thus (1.3) can be rewritten as:

$$
A=A(w, y, \alpha), \frac{\partial A}{\partial y}>0, \frac{\partial A}{\partial \alpha}>0 .
$$

Let the total amount of mangrove area that is remaining in any time period, $t$, be defined as $M$. Thus the total stock of mangrove area at time $t$ available in a country, either for conversion or for preservation, can be denoted as $N>A$, or $N=A+M$. As this is a static model (for cross-sectional analysis) we will assume that $N$ is a given stock, and will be affected by prevailing ecological and coastal conditions, $\beta$, of the country, such as length of coastline, rainfall, tidal conditions, temperature, water quality, and so forth. In addition, the remaining area of mangrove, $M$, may be influenced by the degree of conservation and protection effort, $\gamma$, allocated to their preservation. It follows that

$$
A(w, y, \alpha)+M(\gamma)=N(\beta), \frac{\partial M}{\partial \gamma}>0
$$

Rearranging (1.7) yields

$$
M=M(w, y, \alpha, \beta, \gamma), \frac{\partial M}{\partial y}<0, \frac{\partial M}{\partial \alpha}<0, \frac{\partial M}{\partial \gamma}>0
$$

Equation (1.8) indicates that the remaining mangrove area in a country should decrease with the aggregate output, $y$, of economic activities that depend on 
mangrove conversion, as well as with factors that increase the accessibility of mangrove areas, $\alpha$, but increase with the amount of environmental protection, $\gamma$. Ecological and coastal conditions, $\beta$, and input prices, $w$, should also affect the extent of mangrove areas remaining in a country.

Finally, in recent years, a variety of empirical analyses at both the country and cross-country level have explored the impact on deforestation of institutional factors, such as land use conflict, security of ownership or property rights, political stability and the 'rule of law' (for example, Alston et al. 1999, 2000; Deacon 1994, 1999; Godoy et al. 1998). The main hypothesis tested is that such institutional factors may have important independent influences on deforestation, separate from the effects of other explanatory economic variables. It seems reasonable that the same hypothesis may hold for our analysis, namely that prevailing institutional conditions may be an additional and independent influence on the amount of mangrove area remaining in a country. Denoting $z$ as a vector of institutional indices, such as measures of political stability, ownership security, land use conflict and the 'rule of law', a modified version of (1.8) is

$$
M=M(w, y, \alpha, \beta, \gamma ; z), \frac{\partial M}{\partial y}<0, \frac{\partial M}{\partial \alpha}<0, \frac{\partial M}{\partial \gamma}>0 .
$$

Equation (1.9) is therefore the mangrove area relationship to be estimated through the following cross-country analysis.

\section{DATA AND ESTIMATION APPROACH}

To date, the most reliable source of international mangrove data is the World Mangrove Atlas (Spalding et al. 1997). This database contains estimates of mangrove area for 89 countries, based on various satellite imagery and map sources. ${ }^{2}$ However, the Atlas reports only a single-year estimate of mangrove area for each country. In addition, because different sources are used to provide this estimate, the year in which mangrove area is estimated varies greatly from country to country. Finally, the countries included in the database vary considerably in terms of the size of their mangrove area and their stage of economic development. For example, 22 countries in the sample contain mangrove forests of 2000 ha or less, whereas 28 countries have mangrove areas of 1.5 million ha or more. Although the vast majority of the countries are low and middle-income economies, 14 have GDP per capita ranging from US\$7000 to around US\$23 400 .

Table 1.1 lists the 89 countries from World Mangrove Atlas that were used in the following cross-country estimation of equation (1.9). The year of estimation 
Table 1.1 Countries from World Mangrove Atlas sample

Low income ( $<$ US\$7000 per capita per year)

Low mangrove $(<25 \mathrm{sq} \mathrm{km})$

\begin{tabular}{llll}
\hline Aruba (80) & Grenada (80) & Micronesia (69) & St Vincent (80) \\
Benin (89) & Guam (76) & Samoa (95) & Tonga (72) \\
Djibouti (85) & Mauritania (95) & St Kitts (80) & Vanuatu (72) \\
Dominica (80) & Mayotte (85) & St Lucia (84) &
\end{tabular}

High Mangrove (>25 sq km)

\begin{tabular}{|c|c|c|c|}
\hline Angola (92) & Ecuador (91) & Indonesia (89) & Senegal (85) \\
\hline Antigua (91) & Egypt (92) & $\operatorname{Iran}(70)$ & Seychelles (78) \\
\hline Bangladesh (77) & El Salvador (81) & Kenya (95) & Solomon Is. (95) \\
\hline Belize (92) & Eq. Guinea (60) & Madagascar (79) & Somalia (92) \\
\hline Brazil (91) & Fiji (85) & Malaysia (86) & South Africa (92) \\
\hline Brunei Dar (92) & French Guiana (79) & Mexico (92) & Sri Lanka (92) \\
\hline Cambodia (88) & Gabon (94) & Mozambique (80) & Sudan (92) \\
\hline Cameroon (85) & Gambia (85) & Myanmar (95) & Surinam (78) \\
\hline Colombia (85) & Guadeloupe (80) & Nicaragua (91) & Tanzania (89) \\
\hline Comoros (78) & Guatemala (92) & Pakistan (93) & Thailand (87) \\
\hline Congo (92) & Guinea (80) & Panama (88) & Togo (95) \\
\hline Costa Rica (88) & Guinea-Bissau (90) & Papua NG (70) & Trinidad Tob. (80) \\
\hline Côte d'Ivoire (85) & Guyana (96) & Peru (91) & Venezuela (82) \\
\hline Cuba (89) & Haiti (82) & Philippines (87) & Vietnam (87) \\
\hline Dom. Rep. (84) & India (86) & Puerto Rico (78) & Yemen (87) \\
\hline \multicolumn{4}{|c|}{ High income (>US\$7000 per capita per year) } \\
\hline Bahrain (95) & Bermuda (75) & Qatar (92) & Singapore (90) \\
\hline Barbados (75) & Hong Kong (89) & & \\
\hline \multicolumn{4}{|c|}{ High mangrove ( $>25 \mathrm{sq} \mathrm{km})$} \\
\hline Australia (95) & Cayman Is. (78) & New Zealand (82) & Saudi Arabia (85) \\
\hline Bahamas (92) & Japan (86) & Oman (88) & UAE (82) \\
\hline
\end{tabular}

Note: For each country, the year in which mangrove area is estimated is indicated in parentheses.

Source: Spalding et al. (1997).

of mangrove area for each country is indicated in parentheses. In addition, the table distinguishes between countries with large $\left(>25 \mathrm{~km}^{2}\right)$ as opposed to small $\left(<25 \mathrm{~km}^{2}\right)$ mangrove areas, and those with high ( $>$ US\$7000) per capita income as opposed to middle or low income $(<$ US\$7000).

To estimate equation (1.9), we required cross-country data for the key 
variables in the regression that also matched as closely as possible the year of estimation of mangrove area for each country, as reported in Table 1.1. We were able to find data, or close proxies, for output of mangrove-dependent economic activity $(y)$, accessibility of mangrove areas $(\alpha)$, ecological and coastal conditions $(\beta)$, environmental protection $(\gamma)$ and institutional factors $(z)$. Unfortunately, we were unable to obtain suitable data to represent our input price variable, $w .^{3}$ For the remaining variables in (1.9) we used the following data sources. (Unless indicated otherwise, the data are for the same year of estimated mangrove area for each country reported in Table 1.1.)

\section{Mangrove-dependent economic activity, $y$}

As noted in the introduction, for most countries, mangrove loss is associated with key primary sector economic development activities, such as shrimp aquaculture, over-harvesting of forests, mining, salt production and agricultural expansion in coastal areas. From FAO (2000) we were able to obtain an estimate of total aquaculture production in metric tons of all shrimp and prawn species for the same year of estimated mangrove area for each country reported in Table 1.1. We average total shrimp aquaculture production over the total coastline length of a country. ${ }^{4}$ To represent production, or development, of other key primary economic activities that might cause mangrove loss we employed data on agricultural gross domestic product (GDP) per head of population engaged in agriculture, from World Bank (1998) and FAO (1997). However, mangrove deforestation may not just be related to certain primary sector economic activities but also be affected by the general level of economic development as well as the pace of economic growth in a country. To examine this hypothesis, we also included GDP per capita and GDP annual growth (from World Bank, 1998) in our analysis.

\section{Accessibility of mangrove areas, $\alpha$}

The 'accessibility' of mangrove areas available for conversion may be affected by such factors as roads, coastal infrastructure and the concentration of populations in coastal areas. As an indicator of the state of development of a country's road network, we employed data on the percentage of paved roads (World Bank 1998). For some countries, we were also able to obtain data on the population in coastal urban agglomerations, for 1980, and projections for the year 2000 (WRI 1994).

\section{Ecological and coastal conditions, $\beta$}

The abundance of mangroves found in any country will depend on a number of ecological and coastal conditions, including length of coastline, rainfall, 
tidal conditions, temperature, water quality and so forth. Estimates of the total length of coastline (in kilometers) for 88 of the countries listed in Table 1.1 were obtained from WRI (1994) and National Geographic Society (1981). ${ }^{5}$ Data for only a limited number of countries on average annual rainfall, temperature and tidal range are available from Spalding et al. (1997).

\section{Environmental protection, $\gamma$}

Our theoretical model suggests that the remaining mangrove area found in a country is likely to increase with the amount of environmental protection. Spalding et al. (1997) also provide an estimate of the total number of protected areas for each of the countries listed in Table 1.1. We employed this variable as our indicator of the degree of environmental protection in each country.

\section{Institutional factors, $z$}

As noted above, recent analyses have focused on the way a variety of institutional factors, such as land use conflict, security of ownership or property rights, political stability and the 'rule of law', may affect deforestation. The cross-country database on institutional factors that most closely matches the range of countries and the corresponding years for mangrove area estimates indicated in Table 1.1 is from Banks (1990). For selected countries in Table 1.1, the Banks data set contains data on the number of major cabinet changes (1985 only), constitutional changes (1985 only), government coups (1985 only), political purges (1985 and 1990), government crises (1985 and 1990), guerrilla warfare incidents (1985 and 1990), industrial strikes (1985 and 1990), political assassinations (1985 and 1990) and political revolts (1985 and 1990). The Banks data also include an index of party fractionalization (1985 only). All these institutional variables essentially reflect the degree of political stability in a country. Rather than include each variable separately, we combined them into three different single indicators of overall political stability for each country:

- a political stability index (PSI85) based on the variables for 1985 only (cabinet changes, constitutional changes and government coups plus the party fractionalization index $) ;$

- a political stability index (PSI8590) based on a composite of the 1985 and 1990 observations for the relevant variables (purges, crises, guerrilla warfare, strikes, assassinations revolts and riots) ${ }^{7}$

- a political stability index (PSI) based on the average of the above two indices. 
All three indices range from 0 (highest political stability) to 1 (lowest political stability).

\section{Other economic and demographic variables}

In addition to the various economic, ecological and economic factors identified in our model in the previous section that may determine the size of mangrove area found in a country, other demographic and economic influences may also affect mangrove conversion across countries. To represent these possible exogenous influences, we extended our data set for estimating (1.9) to include several additional variables. These were population density, rural population density, the percentage of the total labor force in agriculture, agricultural raw material exports as a percentage of total merchandise exports, total debt service (as a percentage of exports) and the real rate of interest. The source of all these variables was World Bank (1998).

\section{Estimation approach}

Given that our complete cross-country data set comprises observations for a single year only, estimation of the empirical relationship (1.9) across countries was conducted using ordinary least squares. The estimations were performed on the entire sample of all countries in Table 1.1, a sub-sample of countries with per capita income less than $\$ 7000$ per person, and a sub-sample of countries with mangrove area greater than $25 \mathrm{~km}^{2}$. In all regressions, the Breusch-Pagan chi-squared test indicated the presence of heteroskedasticity, which was adjusted through using White's robust correction of the covariance matrix. All regressions were also tested for the appropriate functional form: linear, semi-log and logarithmic. In every case the linear functional form was preferred. Finally, the independent variables were also examined for multicollinearity, which was rejected in all cases. This was particularly important in ensuring that total shrimp aquaculture production per length of coastline, agricultural GDP per head of population engaged in agriculture, GDP per capita, GDP growth and total coastline length could be included together as independent variables in the estimation of equation (1.9).

Table 1.2 lists the sub-set of variables from our full data set that were employed in the final cross-country regressions of the factors determining the remaining mangrove area of a country. Some of the variables in our complete data set, such as population in coastal urban agglomerations projected for 2000 , tidal range, total debt service and the real rate of interest, proved to have too few observations across countries, and thus their inclusion reduced the sample sizes of the regressions significantly. In addition, none of these variables was found to be significant in the latter regressions, and the overall 
explanatory power of these estimations was poor. Two other ecological variables, average annual rainfall and temperature, plus the remaining exogenous demographic and economic variables (that is, population density, rural population density, the percentage of the total labor force in agriculture and agricultural raw material exports as a percentage of total merchandise exports), were not significant in any regressions. In most cases the inclusion of one or more of these variables distorted the estimation results considerably, as well as reducing the overall explanatory power of the regressions. With the exception of average annual rainfall, none of the above variables was included in the final estimations of equation (1.9), and thus they are not listed in Table 1.2. Finally, of the three indices of political stability, PSI8590 performed consistently better in most regressions. This variable was therefore our preferred indicator of political stability.

The 89 countries in Table 1.1 are drawn from five distinct global geographical zones (Spalding et al. 1997). These are East Asia, South East Asia and South Asia (zone 1); Oceania (zone 2); Latin America and the Caribbean (zone 3); Western (that is, Atlantic Coast) Africa (zone 4); and Eastern (that is, Indian Ocean and Red Sea Coasts) Africa and the Persian Gulf (zone 5). Countries located in zone 1 account for approximately 43 per cent of the total mangrove area of all countries listed in Table 1.1, and countries from zone 3 represent over 31 per cent of total mangrove area. Given that most of the world's remaining mangrove areas are largely found in these two zones, we included dummy variables for countries from zone 1 and zone 3, respectively, in our cross-country regressions (see Table 1.2). The presence of dummy variables for these zones allows us to test the hypothesis that the mean (expected) values of remaining mangrove area in zones 1 and 3 are greater than in other geographical regions (that is, zones 2, 4 and 5).

Finally, given that the data range for mangrove area estimates by country is from 1960 to 1996, alternative dummy variables for country observations from the earlier years of the sample were also employed. These included dummies for observations for years before 1975, 1981 and 1985. In addition, a year indicator variable was also included in alternative versions of the regressions. However, none of the dummy variables or the year indicator variable proved significant, nor did they improve the explanatory power of the regressions. These variables were therefore dropped from the estimations.

\section{ESTIMATION RESULTS}

The cross-country regressions of equation (1.9) for the sample of all countries are reported in Table 1.3, along with the relevant test statistics. Four different versions of the regression are indicated. Model 1 excludes both the GDP per 
Table 1.2 Definitions of variables used in cross-country regressions

\begin{tabular}{|c|c|}
\hline Variable & Definition \\
\hline MANGROVE & Mangrove area $\left(\mathrm{km}^{2}\right)$, year varies (Spalding et al. 1997). \\
\hline AREAS & $\begin{array}{l}\text { Number of protected areas, same year as MANGROVE } \\
\text { (Spalding et al. 1997) }\end{array}$ \\
\hline AQUAS & $\begin{array}{l}\text { Total shrimp and prawn aquaculture production (metric } \\
\text { tons), same year as MANGROVE, per length of coastline } \\
(\mathrm{km})(\text { FAO 2000; WRI 1994) }\end{array}$ \\
\hline AGDPAP & $\begin{array}{l}\text { Agriculture value added divided by population engaged in } \\
\text { agriculture (constant } 1987 \text { US\$/person), same year as } \\
\text { MANGROVE (FAO 1997; World Bank 1998) }\end{array}$ \\
\hline GDPG & $\begin{array}{l}\text { GDP growth (annual \%), same year as MANGROVE (World } \\
\text { Bank 1998) }\end{array}$ \\
\hline GDPPC & $\begin{array}{l}\text { GDP per capita (constant } 1987 \text { US\$/person), same year as } \\
\text { MANGROVE (World Bank 1998) }\end{array}$ \\
\hline ROADS & $\begin{array}{l}\text { Percentage of paved roads, same year as MANGROVE } \\
\text { (World Bank 1998) }\end{array}$ \\
\hline COAST & Length of coastline (km) (WRI 1994) \\
\hline CUP1980 & $\begin{array}{l}\text { Population in coastal urban agglomerations ('000s) (WRI } \\
\text { 1994) }\end{array}$ \\
\hline PSI8590 & Political stability index ${ }^{\mathrm{a}}$ \\
\hline RAIN & Mean monthly annual rainfall (mm) (Spalding et al. 1987) \\
\hline DUM1 & Dummy for countries from zone 1 (Asia) ${ }^{b}$ \\
\hline DUM3 & $\begin{array}{l}\text { Dummy for countries from zone } 3 \text { (Latin America and } \\
\text { Caribbean) }\end{array}$ \\
\hline
\end{tabular}

Notes:

${ }^{\text {a }}$ Based on Banks (1990); see text for explanation.

${ }^{\mathrm{b}}$ Includes countries from East Asia, Southeast Asia and South Asia.

capita and growth variables. Model 2 includes GDP growth only, and Model 3 includes GDP per capita only. The fourth model displayed in Table 1.3 includes an additional ecological variable (RAIN) to Model 3. ${ }^{8}$

Model 4 is the preferred regression. The parameter estimate for GDP per capita (GDPPC) in the latter regression is significant and positive. Although average annual rainfall is significant only at the 10 per cent level, it is positively correlated with mangrove area across countries. In addition the explanatory power of Model 4 , as measured by the adjusted $R^{2}$, is the highest for all four regressions.

In all four models the estimated coefficients for agricultural GDP per person employed in agriculture (AGDPAP) are highly significant and negative. In the 


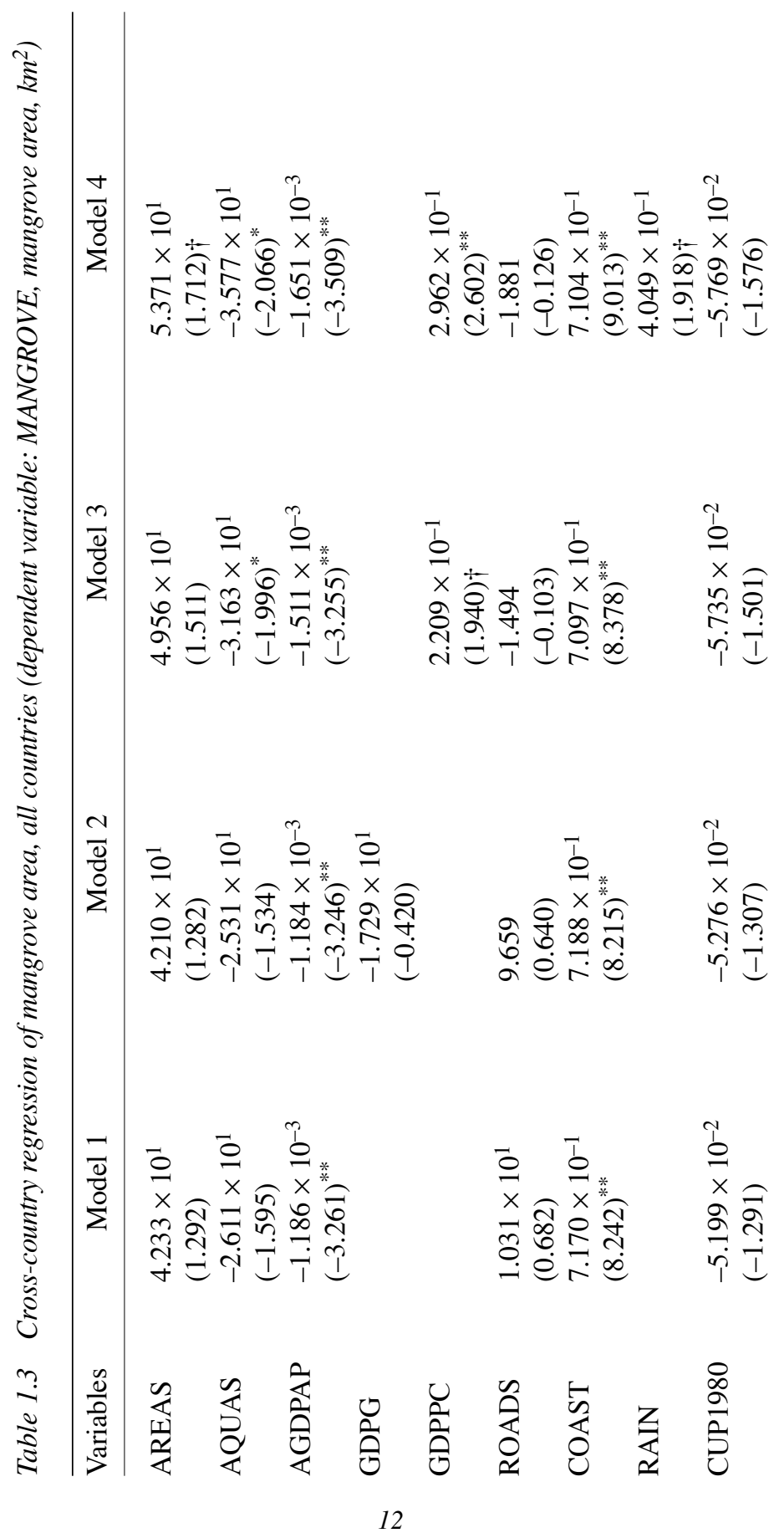




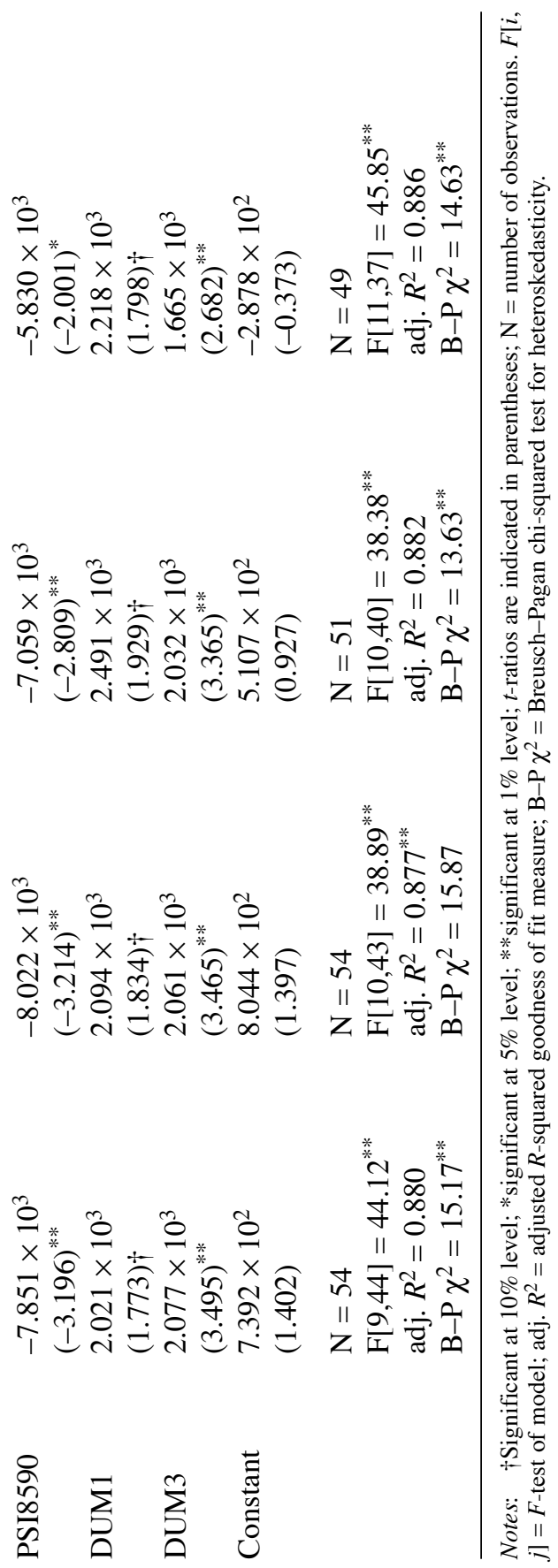


preferred regression (Model 4), as well as in Model 3, the parameter estimate for shrimp aquaculture production (AQUAS) is also significant and negative. Thus the hypothesis that an increase in primary sector activities reduces the remaining mangrove area of a country cannot be rejected.

Model 2 indicates that GDP growth (GDPG) is not a significant variable in the regressions. Thus mangrove deforestation does not appear to be affected by a country's rate of economic growth. In contrast, in the preferred regression of Model 4 GDPPC is significant and positive. This implies that the hypothesis that the general level of economic development (that is, GDP per capita) in a country influences mangrove deforestation cannot be rejected. Across the sample of all countries, an increase in GDP per capita tends to be associated with more remaining mangrove areas in a country. The most reasonable explanation is that, as an economy develops, manufacturing and tertiary economic activities are more prevalent, and these sectors are less likely to be responsible for widespread mangrove deforestation. ${ }^{9}$

Finally, the dummy variable for zone 3 was significant and positive in all four regressions of Table 1.3, and the dummy variable for zone 1 was positive and significant at the 10 per cent level. Thus we cannot reject the hypothesis that the mean values of remaining mangrove areas in zone 1 (East Asia, South East Asia and South Asia) and zone 3 (Latin America and the Caribbean) are greater than in other geographical regions. Of the remaining variables, the length of coastline and the political stability index were highly significant and positive across all four estimations, whereas the percentage of paved roads, the number of protected areas and coastal urban population in 1980 were not significant.

Table 1.4 reports the two best regressions of equation (1.9) with respect to each of the two sub-samples of countries, those with per capita income less than $\$ 7000$ per person and countries with mangrove area greater than $25 \mathrm{~km}^{2}$. Models 1 and 2 in Table 1.4 are for low and middle-income countries (that is, with GDP per capita less than $\$ 7000$ per person). Models 3 and 4 in Table 1.4 are for countries with relatively large remaining mangrove areas (that is, with mangrove areas greater than $25 \mathrm{~km}^{2}$ ).

Neither GDP per capita nor GDP growth proved significant in any of the regressions for low and middle-income countries, and the overall explanatory power of these estimations was poor. Thus these variables are excluded in the regressions reported in Table 1.4. The difference between the two reported regressions is that Model 2 includes RAIN, whereas Model 1 does not. However, RAIN appears not to be significant in Model 2, and so Model 1 is the preferred regression.

In both Model 1 and Model 2 the estimated coefficient for shrimp aquaculture production (AQUAS) and the coefficient for agricultural GDP per person employed in agriculture (AGDPAP) are negative, but not significant. Thus for 


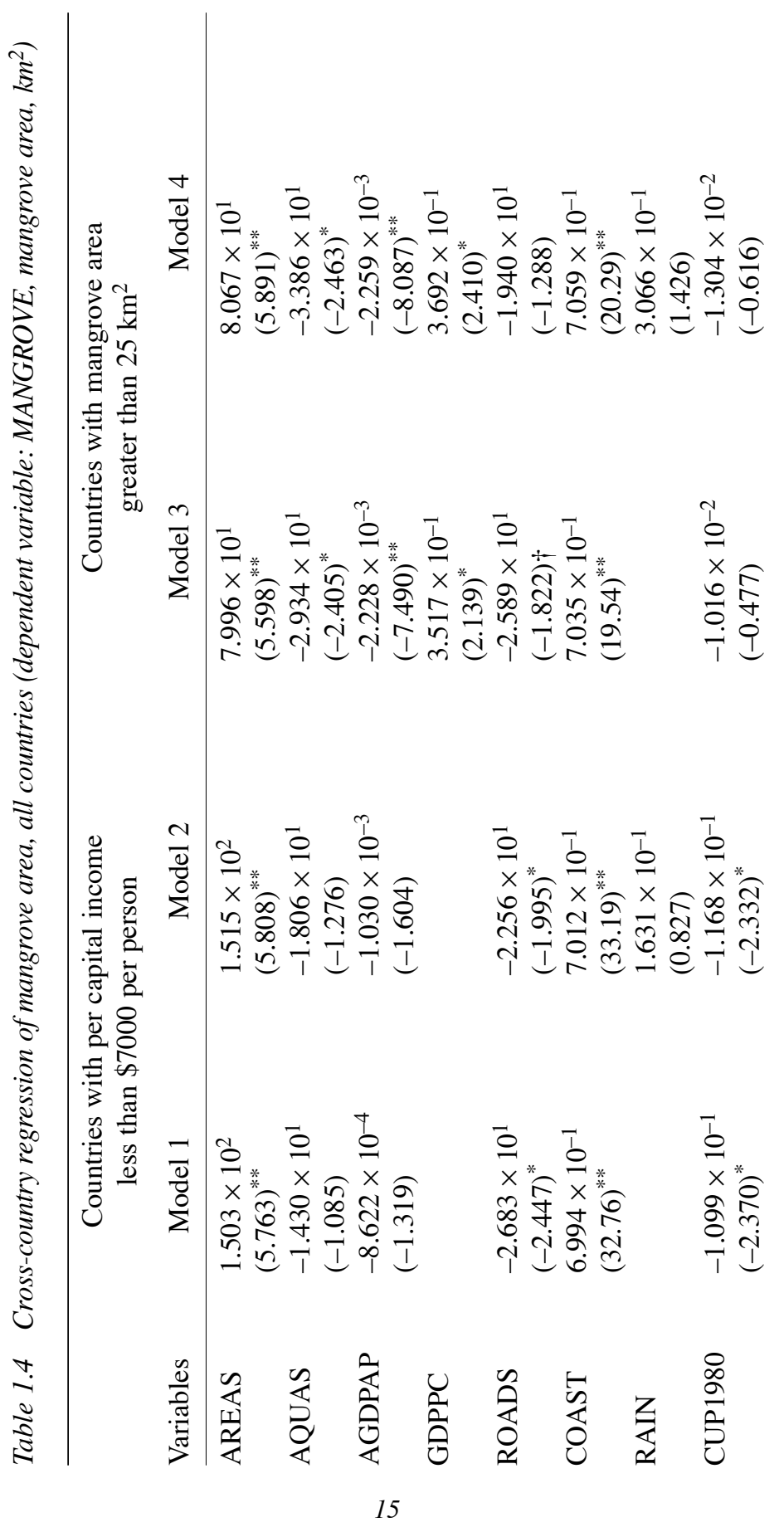




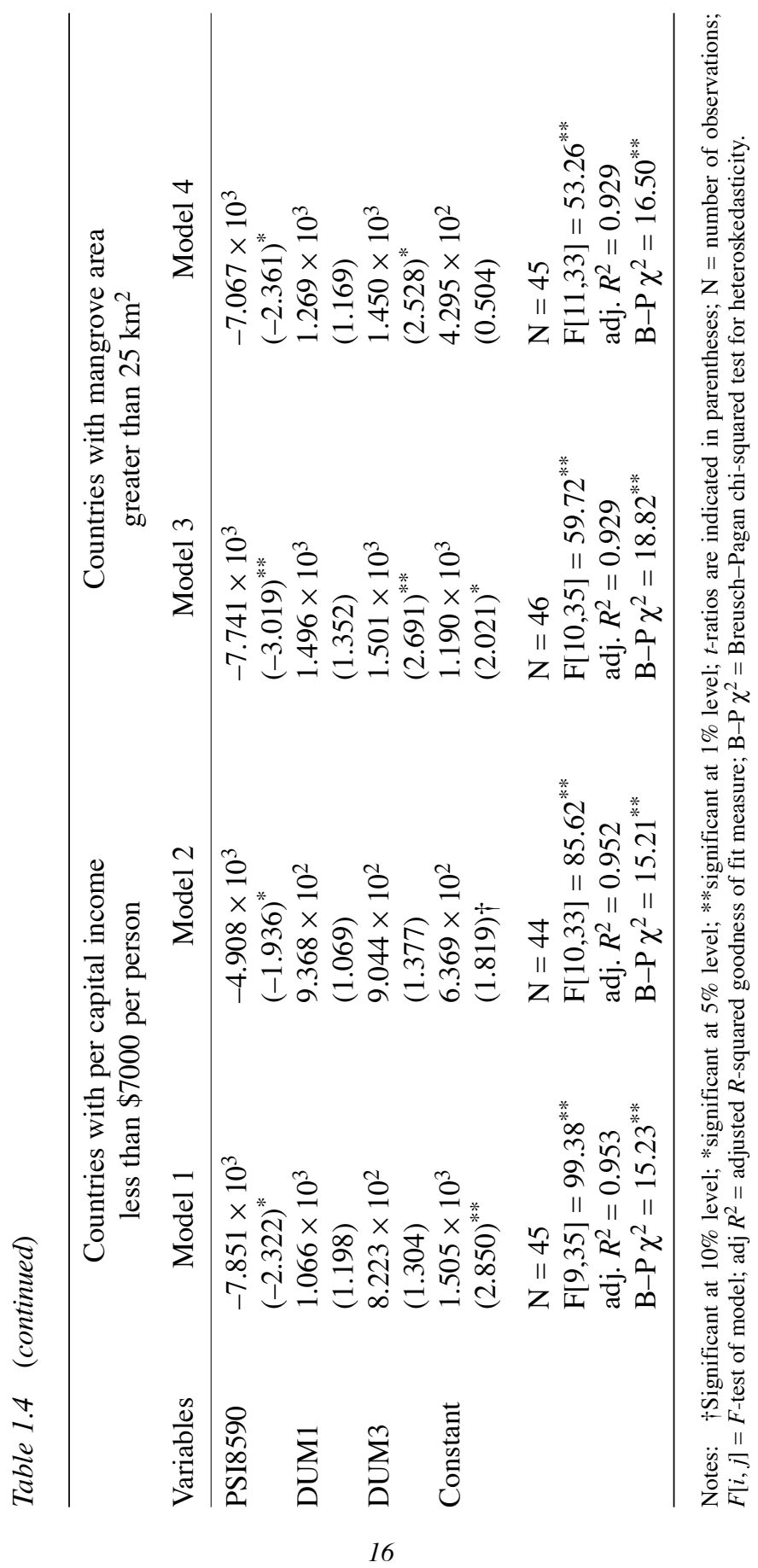


low and middle-income countries the hypothesis that an increase in primary sector activities reduces the remaining mangrove area of a country can be rejected.

In sum, Models 1 and 2 suggest that neither primary production nor overall economic development and growth appear to be significant in influencing the remaining mangrove areas across all low and middle-income countries. In contrast, the key variables affecting mangrove areas for this group of countries appear to be the length of coastline, the number of protected areas, coastal urban population, political stability and the percentage of paved roads. The coefficients of these variables all have the same signs as predicted by our theoretical model. Coastline length is once again positively associated with remaining mangrove area. Mangrove areas increase with environmental protection, but decline as these forests become more accessible owing to an improved road network, as coastal urban populations rise or as political instability increases in low and middle-income economies.

Finally, the zonal dummy variables were not significant in either Models 1 or 2 of Table 1.4, indicating that for low and middle-income countries there is no geographical difference across the five zones with respect to the regressions of remaining mangrove area.

As noted above, Models 3 and 4 in Table 1.4 are the best regressions for countries with relatively large remaining mangrove areas (that is, with mangrove areas greater than $25 \mathrm{~km}^{2}$ ). In both regressions, GDP per capita is significant and is included. ${ }^{10}$ The main difference between the two reported regressions is that Model 4 includes RAIN, whereas Model 3 excludes this ecological variable. However, RAIN is not significant in Model 4, and so Model 3 is the preferred regression.

In both models the estimated coefficients for both shrimp aquaculture production per length of coastline (AQUAS) and agricultural GDP per person employed in agriculture (AGDPAP) are significant and negative. Thus, for economies with mangrove areas greater than $25 \mathrm{~km}^{2}$, the hypothesis that an increase in primary sector activities reduces the remaining mangrove area of a country cannot be rejected. The parameter estimate for GDP per capita (GDPPC) in Models 3 and 4 is also significant and positive. For countries with large mangrove areas, one cannot reject the hypothesis that the general level of economic development (that is, GDP per capita) affects mangrove deforestation. Moreover, an increase in GDP per capita tends to be associated with more remaining mangrove areas in a country, suggesting that, as a country with large mangrove areas develops economically, less deforestation occurs.

The dummy variable for zone 3 was significant and positive for both regressions for countries with large mangrove areas. Thus, for these countries, the hypothesis that the mean values of remaining mangrove areas in Latin America and the Caribbean (zone 3) are greater than in other geographical 
regions cannot be rejected. Of the remaining variables, the number of protected areas, the length of coastline and the political stability index are significant in both Models 3 and 4, and the percentage of paved roads is significant at the 10 per cent level in our preferred Model 3. The signs are once again as predicted by our theoretical model. For countries with large mangrove areas, these areas are greater for countries with longer coastlines and more environmental protection, but decline for countries with increased political instability and easier forest access due to an improved road network.

Table 1.5 indicates the elasticity estimates for the explanatory variables in the preferred regressions of mangrove area for all three samples of countries: (a) the sample of all countries (Table 1.3, Model 4); (b) the sub-sample of countries with per capita income less than $\$ 7000$ per person (Table 1.4, Model 1 ); and (c) the sub-sample of countries with mangrove area greater than 25 $\mathrm{km}^{2}$ (Table 1.4, Model 3). The elasticity estimates facilitate comparisons across these three regressions.

Across the entire sample of countries, and for countries with large mangrove areas, the estimated elasticities for both aquaculture production (AQUAS) and agricultural GDP per person employed in agriculture (AGDPAP) are highly significant and negative. Increases in overall agricultural GDP per person employed in agriculture have the larger impact on

Table 1.5 Estimated elasticities of the cross-country regressions of mangrove area

\begin{tabular}{lccc}
\hline Variables & $\begin{array}{c}\text { All countries } \\
(\mathrm{N}=89)\end{array}$ & $\begin{array}{c}\text { Countries with per } \\
\text { capita income } \\
\text { less than } \$ 7000 \\
\text { per person } \\
(\mathrm{N}=76)\end{array}$ & $\begin{array}{c}\text { Countries with } \\
\text { mangrove area } \\
\text { greater than } \\
25 \mathrm{~km}^{2} \\
(\mathrm{~N}=67)\end{array}$ \\
\hline AREAS & $0.181 \dagger$ & $0.347^{* *}$ & $0.251^{* *}$ \\
AQUAS & $-0.018^{*}$ & -0.007 & $-0.014^{*}$ \\
AGDPAP & $-1.089^{* *}$ & -0.292 & $-1.046^{* *}$ \\
GDPPC & $0.647^{* *}$ & - & $0.486^{*}$ \\
ROADS & -0.032 & $-0.349^{*}$ & $-0.307 \dagger$ \\
COAST & $1.104^{* *}$ & $0.889^{* *}$ & $1.011^{* *}$ \\
RAIN & $0.351^{*}$ & - & - \\
CUP1980 & -0.131 & $-0.200^{*}$ & -0.019 \\
PSI8590 & $-0.165^{*}$ & $-0.165^{*}$ & $-0.195^{* *}$ \\
\hline
\end{tabular}

Notes: $†$ Significant at $10 \%$ level; *significant at $5 \%$ level; **significant at $1 \%$ level; $\mathrm{N}=$ number of observations in full sample. Elasticities calculated using all the non-missing observations of the full sample for each variable. 
mangrove loss. A 10 per cent rise in AGDPAP leads to around a 10.9 per cent fall in mangrove area for all countries, and a 10.5 per cent decline for countries with more than $25 \mathrm{~km}^{2}$ of mangroves. In comparison, a 10 per cent increase in shrimp aquaculture production is associated with 0.18 per cent and 0.14 per cent declines in the respective sub-samples.

For all countries and for countries with large mangrove areas, the level of economic development, as represented by the GDP per capita of a country, is positively associated with greater mangrove area. A 10 per cent increase in GDP per capita will lead to a 6.5 per cent rise in mangrove area across all countries and a 4.9 per cent increase for countries with large mangrove areas.

Several explanatory variables also have impacts on remaining mangrove areas, although, with the exception of length of coastline and political instability, most variables were not significant across the three regressions. However, in all cases the effects of the explanatory variables were the same as predicted by our theoretical model. The number of protected areas, coastline length and rainfall had positive effects on mangrove area, whereas the percentage of paved roads, coastal urban population and political instability had negative impacts.

A country with a 10 per cent greater coastline length will have 11 per cent more mangrove area across all countries, 8.9 per cent more in low and middleincome economies and 10.1 per cent more in countries with large mangrove areas. A 10 per cent increase in political instability is associated with a 1.7 per cent decline in mangrove area across all countries and in low and middleincome countries, and a 2 per cent decline in countries with mangrove areas greater than $25 \mathrm{~km}^{2}$. A 10 per cent increase in environmental protection is associated with a 3.5 per cent increase in mangrove area in low and middleincome economies and a 2.5 per cent increase in countries with large mangrove areas. A 10 per cent rise in the percentage of paved roads and coastal urban populations lead respectively to 3.5 per cent and 2 per cent falls in mangrove area in low and middle-income economies. Finally, although the variable is significant only at the 10 per cent level, a country with 10 per cent more rainfall is likely to have 3.5 per cent more mangroves across all countries.

\section{CONCLUSION}

This chapter has sought to analyze the role of economic development, and in particular primary sector activities dependent on mangrove conversion, in causing the rapid decline in coastal mangrove areas across many countries of the world. From a theoretical model of economic activity and mangrove conversion, in which the demand for land by converting activities leads to 
mangrove loss, we established a relationship between remaining mangrove area, the level of economic activity and other important causative factors. Mangrove area is expected to be a decreasing function of aggregate economic activities, such as shrimp aquaculture and agricultural expansion, that may involve the conversion or depletion of mangroves, and to be increasing with the amount of environmental protection. Ecological and coastal conditions, the accessibility of mangrove areas and institutional factors such as political stability should also have an influence.

The mangrove area relationship emerging from our theoretical model was then estimated empirically through a cross-sectional analysis of 89 countries, as well as for sub-samples of middle and low-income economies and countries with mangrove areas greater than $25 \mathrm{~km}^{2}$. The main purpose of the empirical analysis was to examine the hypotheses that mangrove deforestation may be (a) due to certain mangrove-dependent primary sector economic activities (that is, aquaculture production and agricultural GDP per person employed in agriculture) and (b) affected by the general level of economic development and/or current rate of growth in a country (represented by GDP per capita and GDP annual growth, respectively).

With regard to the first hypothesis, the regressions across all samples of countries and for countries with mangroves larger than $25 \mathrm{~km}^{2}$ provide some evidence that mangrove loss is associated with expansion of shrimp aquaculture production along coastlines and primary sector (that is, agricultural) activities generally. Of these two factors associated with mangrove deforestation, increases in overall agricultural GDP per person employed in agriculture have the larger impact on mangrove loss.

With regard to the second hypothesis, there is some evidence that the level of economic development of a country affects the amount of its remaining mangroves. However, the relationship between mangrove area and the general economic performance of a country varies considerably depending on the sample of countries. For all countries and for countries with large mangrove areas, the level of economic development appears to be positively associated with greater mangrove area. GDP per capita may be associated with expanding manufacturing and tertiary economic activities, and these economic sectors are less likely to be responsible for widespread mangrove deforestation. However, GDP per capita is not significantly associated with mangrove loss in the sample of low and middle-income countries, and economic growth does not appear to influence mangrove area at all.

The only ecological variable to have a consistent effect across regressions was length of coastline. As expected, a country with a greater coastline length will have more mangrove area. There was some evidence that a country with greater rainfall will also have more mangrove area, but this variable was significant only at the 10 per cent level and only for the regression sample for 
all countries (Model 4 in Table 1.3). One interesting finding of the analysis was that political instability appears to be strongly associated with mangrove deforestation in all regressions.

Other explanatory factors also influenced the mangrove area of a country, although not necessarily for all versions and samples of the regressions used to estimate equation (1.9). However, in all cases, the effects of these variables were the same as predicted by our theoretical model. For low and middleincome economies and for countries with large mangrove areas, an increase in environmental protection is associated with an increase in mangrove area, whereas a rise in the percentage of paved roads is linked to a decline in mangroves (see Table 1.5). For low and middle-income countries an increase in coastal population is also associated with mangrove loss.

Overall, our analysis has been able to identify some economic conditions that are most likely to be associated with greater mangrove loss. We find some evidence that mangrove loss is associated with expansion of shrimp aquaculture production along coastlines and primary sector (that is, agricultural) activities generally, but not necessarily in all low and middle-income countries. Instead, it appears that countries with large mangrove areas are particularly susceptible to mangrove conversion from primary sector activities. Much of the current literature on global mangrove deforestation has focused on the influence of shrimp aquaculture expansion. Interestingly, however, our crosscountry analysis suggests that increases in overall agricultural GDP per person employed in agriculture have the larger impact on mangrove loss. Nevertheless, from a policy perspective, there seems to be considerable scope for countries to reduce mangrove deforestation through mitigating the impacts of all primary sector activities in coastal areas, including shrimp aquaculture, on remaining mangrove areas.

We also find some evidence that an increase in the level of overall economic development of a country, as reflected in its GDP per capita, may actually be associated with reduced mangrove loss. As a country develops economically, it will become more dependent on expanding manufacturing and tertiary economic activities, and these economic sectors are less likely to be responsible for widespread mangrove deforestation. Again, it appears that countries with large mangrove areas are particularly susceptible to this mitigating effect of overall economic development on mangrove loss.

Our analysis suggests that some forms of economic development in some countries are likely to be associated with widespread mangrove loss. For example, a country endowed with large mangrove areas that is expanding its shrimp aquaculture production in coastal areas and is highly dependent economically on primary sector (that is, agricultural) activities generally is likely to experience greater mangrove deforestation. As that country develops economically, however, it may become less dependent on the latter activities 
and thus reduce its mangrove loss. On the other hand, if the country is politically unstable but has accessible mangrove areas, as the result of improved road networks, these factors will also contribute to increased mangrove loss. However, increased investment in environmental protection will counteract this loss to some extent. Perhaps this is one encouraging policy option emerging from our analysis. If the international community can provide low and middle-income economies with technical and financial assistance to increase their protection and conservation efforts, particularly of vulnerable coastal mangrove systems, this may be one way of slowing down rates of mangrove loss globally.

Finally, there are a number of important caveats to this analysis, given the limited data set. It would have been preferable to have mangrove data for more than one year across countries, but unfortunately such time series observations are not available for many countries. The absence of such time series data limited our ability to employ more sophisticated panel analyses of changes in mangrove area over time. A second problem with the data set is that some key ecological variables, such as temperature and tidal levels, were incomplete for many countries, and other important ecological indicators, such as levels of coastal pollution, are not available. Other variables, such as rainfall, percentage of roads paved and number of protected areas, are national aggregates rather than specific to coastal areas where mangroves are located. Even key economic variables were not always available for all the countries in the sample for the years indicated in Table 1.1. As can be seen in Tables 1.3 and 1.4 , the result was that the sample sizes of regressions were often smaller than the full sample of 89 countries.

Given these limitations, the analysis and conclusions of this chapter regarding the potential impacts of economic development on mangrove deforestation across countries must be considered preliminary. Nevertheless, as this chapter represents a first attempt to develop a formal analysis of the economic factors determining mangrove loss worldwide, we hope that our analysis will lead to improved data collection and analysis for further work in this important area.

\section{NOTES}

1. Mangrove swamps are considered very suitable for shrimp farming because the areas are flooded with brackish, stagnant water that is ideal for aquaculture (Kongkeo 1997).

2. Although the list of countries covered by the World Mangrove Atlas is fairly comprehensive, there are a couple of notable omissions, such as Nigeria, which has one of the largest areas of mangroves in the world (WRI 1996), and the United States. Curiously, the Atlas does not report mangrove area for the entire United States but only for Florida.

3. Our preference was to use rural wage rates across countries as our main input price variable, as the available evidence suggests that in many countries rural labor is a major input in both the clearing of mangroves and in activities such as aquaculture and agriculture that depend 
on mangrove conversion (Spalding et al. 1997; WCMC 1994; WRI 1996). However, obtaining a cross-country data set on rural wage rates for the year of estimation of mangrove area for each country, as reported in Table 1.1, was not possible. Similar problems occurred for other input price data, such as for fertilizers, insecticides and other key agricultural inputs.

4. As noted in the introduction, extensive shrimp and prawn aquaculture production in coastal areas is most likely to be responsible for conversion of mangroves. If a country's shrimp aquaculture production is small relative to its coastline then there is likely to be less impact on the total mangrove area of that country.

5. The one exception is Micronesia.

6. The number of cabinet changes, constitutional changes and coups were each converted into a weighted index variable using the formula $X_{i} / \operatorname{Max}|X|$, where $X_{i}$ is the observation for the $i^{\text {th }}$ country and Max $|X|$ is the maximum observation in the cross-country sample. The three resulting weighted index variables, along with the party fractionalization index, were then averaged into the single political stability index variable, using the standard formula $\Sigma X_{i j} / N_{j}$ where $X_{i j}$ is the index value of the $j^{\text {th }}$ political variable for the $i^{\text {th }}$ country and $N_{j}$ is the number of political variables.

7. The composite 1985 and 1990 data set for each of the political variables (purges, crises, guerrilla warfare, strikes, assassinations, revolts and riots) was created by selecting the observation from either 1985 or 1990, depending on which year more closely corresponded to the single-year estimate of mangrove area for each country in Table 1.1. The resulting data set for each variable was then converted into a weighted index using the formula $X_{i} / \mathrm{Max}|X|$, and then all the indexed variables were averaged into the single political stability index variable, using the standard formula $\Sigma X_{i j} / N_{j}$ :

8. Other variants than the four models depicted in Table 1.3 were also estimated. For example, including both GDP per capita and GDP growth did not improve upon Model 3, and the coefficient for GDPG was insignificant. Including a GDP per capita squared term in Model 3 did not improve the regression results, and the coefficient for the squared GDPPC term was also not significant. Thus an 'environmental Kuznets curve' income effect can be rejected in this analysis.

9. This finding and explanation is consistent with some cross-country studies of deforestation, especially for tropical countries, which also report a negative relationship between forest loss and GDP per capita. For recent reviews, see Kaimowitz and Angelsen (1998) and Barbier and Burgess (2001).

10. Replacing GDP per capita with GDP growth, or including both variables together, in Models 3 and 4 did not improve the explanatory power of the estimations, and the coefficient for GDPG was always insignificant. 
Edward B. Barbier and Mark Cox - 9781843769668 Downloaded from PubFactory at $\bullet 4 / 26 / 2023$ $04: 54: 26 \mathrm{AM}$ 